\title{
Avaliação de modelos agrometeorológicos para estimativa da produtividade na cultura do milho
}

\author{
Evaluation of models agrometeorologicals for productivity estimation in \\ corn culture
}

\section{Evaluación de modelos agrometeorológicos para la estimativa de la productividad en la cultura del maíz}

\author{
Claudia Cardoso dos Santos ${ }^{1}$ \\ Glauce Portela de Oliveira ${ }^{1}$ \\ Recebido em 07/03/2018 ; revisado e aprovado em 07/07/2018; aceito em 20/07/2018 \\ DOI: http://dx.doi.org/10.20435/inter.v0i0.1875

\begin{abstract}
Resumo: Objetivou-se avaliar modelos agrometeorológicos para estimativa da produtividade na cultura do milho, determinando quais implicações acarretaram as variações de produtividade e o melhor modelo ajustado para as condições avaliadas. Foram utilizadas séries de dados climatológicos referentes a três safras de milho em Chapadão do Sul, MS. O método de estimativa da produtividade agroclimática para a região de estudo mostrou-se o melhor e eficiente para estimar a produção de milho.
\end{abstract}

Palavras-chave: Zea mays, produtividade potencial, produtividade agroclimática

Abstract: The objective of this study was to evaluate agrometeorological models to estimate productivity in maize crop, determining the implications of the changes in productivity and the best model adjusted for the conditions evaluated. Clusters of climatological data were used for three maize crops in Chapadão do Sul- MS. The method of estimation of the agroclimatic productivity for the region of study was the best and efficient one to estimate the corn production.

Keywords: Zea mays, potential productivity, income agroclimatic.

Resumen: Se objetivó evaluar modelos agrometeorológicos para estimación de la productividad en el cultivo del maíz, determinando cuáles las implicaciones acarrearon las variaciones de productividad y el mejor modelo ajustado para las condiciones evaluadas. Se utilizaron series de datos climatológicos referentes a tres cosechas de maíz en Chapadão do Sul- MS. El método de estimación de la productividad agroclimática para la región de estudio se mostró la mejor y eficiente para estimar la producción de maíz.

Palabras clave: Zea mays, productividad potencial, rendimiento agroclimático

\section{INTRODUÇÃO}

O milho é um dos cereais mais importantes como fonte de energia para humanos e animais, destacando-se como uma das culturas de maior produção de grãos (FOOD AND AGRICULTURE ORGANIZATION OF THE UNITED NATIONS [FAO], 2008 ). Colhem-se, em média, 14 milhões de hectares a cada safra, o que coloca o país em terceiro lugar mundial em área colhida, com produção próxima de 59 milhões de toneladas, em 2008 (INSTITUTO BRASILEIRO DE GEOGRAFIA E ESTATÍSTICA [IBGE], 2009).

A quantificação dos efeitos da variabilidade climática em culturas agrícolas e, consequentemente, o impacto sobre a produção são realizados através dos modelos agrometeorológicos. Estes além de fornecer dados para alimentar os sistemas de previsão de safras agrícolas, permitem identificar estresse hídrico ao longo do ciclo da cultura, cujos impactos na produtividade podem ser detectados e avaliados (ROSA et al., 2010; DOORENBOS; KASSAM, 1979).

Embora o milho responda à interação de todos os elementos climáticos, pode-se considerar que a radiação solar, a precipitação e a temperatura são os que mais influenciam, pois atuam

\footnotetext{
${ }^{1}$ Universidade Federal de Mato Grosso, Rondonópolis, Mato Grosso, Brasil.
} 
diretamente nas atividades fisiológicas, interferindo na produção de matéria seca e de grãos (BRACHTVOGEL et al., 2009).

A melhoria da produtividade de uma cultura pode estar associada com maior tolerância a diferentes estresses ambientais e assim resultar em aumento da estabilidade de produtividade. Para o cultivo do milho, deve-se levar em consideração muitos fatores de ordem biótica e abiótica, mas a decisão para época de semeadura, uso de insumos, objetivando redução das limitações ambientais, e mitigação dos efeitos climáticos no cultivo são de fundamental importância (GALON et al., 2010 ).

Desse modo, o objetivo foi avaliar modelos agrometeorológicos para estimativa da produtividade na cultura do milho, comparando-se a produtividade real obtida com os resultados simulados através de dois métodos, determinando quais implicações acarretaram as variações de produtividade e o melhor modelo ajustado para as condições avaliadas.

\section{MATERIAIS E MÉTODOS}

A área de estudo (Figura 1) abrangeu uma área agrícola, localizada em Chapadão do SulMS, a $18^{\circ} 48^{\prime} 459^{\prime \prime}$ de Latitude sul e 52 $2^{\circ} 5^{\prime} 003^{\prime \prime}$ de Longitude oeste, com área total de cultivo de milho de 387 ha-1, cultivados com o híbrido P30F53H de ciclo precoce.

Figura 1 - Mapa de localização da região de estudo

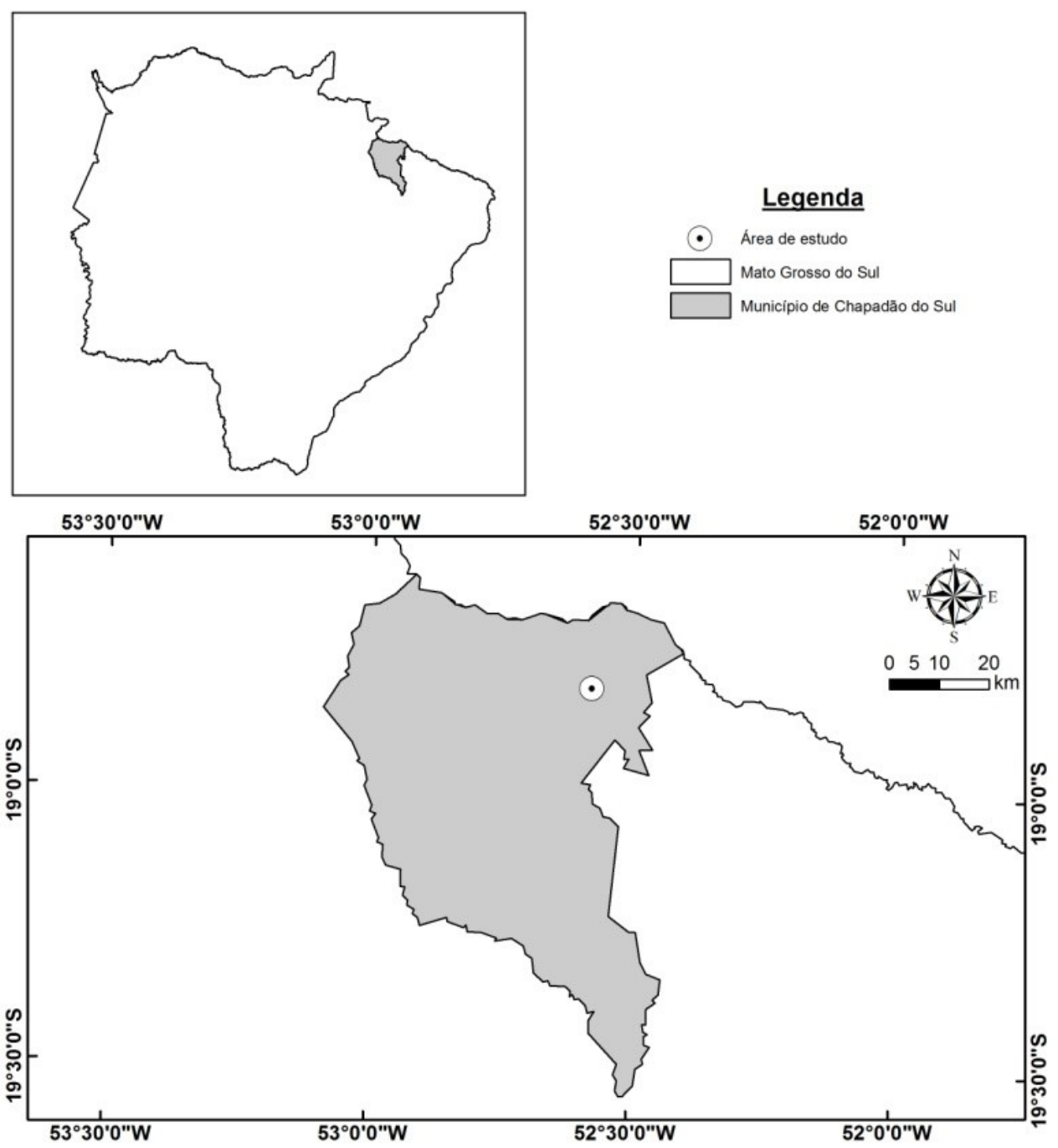

Fonte: Elaborado pelos autores (2014). 
A região de estudo apresenta clima tropical quente (FAO, 1978), com temperaturas médias superiores a $18^{\circ} \mathrm{C}$, consequentemente adequado ao cultivo do milho que se desenvolve principalmente em temperaturas de $24^{\circ} \mathrm{C}$ a $30^{\circ} \mathrm{C}$.

Na Figura 2, é apresentado o fluxograma indicando as etapas que foram utilizadas para obtenção dos cálculos dos modelos agrometeorológicos de produtividade.

Figura 2 - Fluxograma de etapas realizadas para a classificação de áreas

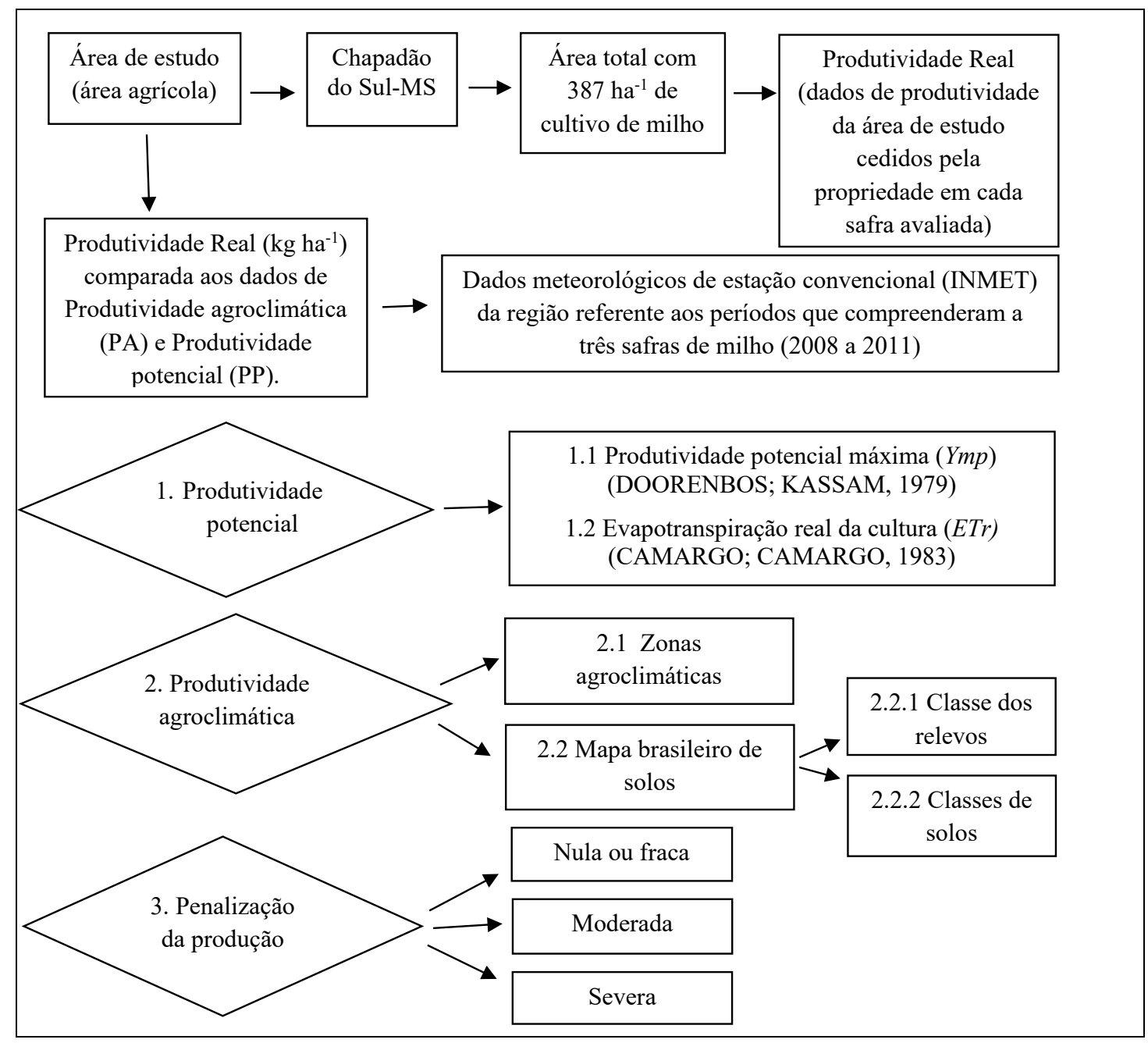

Fonte: Elaborado pelos autores (2014).

A produtividade média dessa área (Produtividade Real) foi, portanto, comparada aos dados de Produtividade agroclimática (PA) e Produtividade potencial (PP).

Para obtenção dos dados para o cálculo das produtividades (potencial e agroclimática) para a região de estudo, foram utilizados dados meteorológicos da região obtidos em uma estação convencional (latitude de $19^{\circ} 75^{\prime} \mathrm{S}$, longitude de $51^{\circ} 18^{\prime} \mathrm{W}$ e altitude de $331.25 \mathrm{~m}$ ) referente aos períodos que compreenderam as safras de milho de 2008/2009, 2009/2010 e 2010/2011, disponibilizados pelo Instituto Nacional de Meteorologia (INMET).

Produtividade potencial: O modelo agrometeorológico utilizado para o cálculo da produtividade potencial da cultura do milho foi o modelo proposto por Doorenbos e Kassam (1979), que considera o potencial máximo de produtividade (Ymp) e a evapotranspiração da cultura 
(Etc), em que: Ymp = cL.cN.cH.G.[F(0.8 + 0.01.ym)], onde:

Ymp = potencial máximo de produtividade (kg ha-1);

$\mathrm{CL}=$ correção do desenvolvimento da cultura e da área foliar;

cN = correção para produção de matéria seca;

$\mathrm{cH}=$ correção para índice de colheita;

$\mathrm{G}=$ período total de crescimento (dias)

$F$ = fração do dia em que o céu está nublado;

ym = máxima taxa de produção de matéria seca bruta foliar para uma cultura em determinado clima;

Evapotranspiração real da cultura: baseia-se nos resultados obtidos de evapotranspiração de referência (ETo), que indica a perda de água de uma superfície vegetada, em crescimento ativo e sem restrição hídrica, que cobre totalmente o solo (FAO, 1978), onde: $E T o=0,01$.Qo.Tmed, em que:

Qo - irradiância solar global extraterrestre $(\mathrm{mm} \mathrm{d}-1)$

Tmed - temperatura média do $\operatorname{ar}\left({ }^{\circ} \mathrm{C}\right)$

ND - número de dias do período considerado.

Desse modo, a evapotranspiração real da cultura (ETr) foi estimada pelo método de Camargo e Camargo (1983), que está representado pela equação: ETr = ETo .Kc .Ks, em que:

Kc- coeficiente da vegetação ou da cultura

Ks- coeficiente que depende da umidade do solo

Produtividade agroclimática: De acordo com o período de crescimento das culturas, estima-se a produtividade agroclimática, onde ocorre uma penalização da produção. Essa análise é feita com base na produtividade potencial e leva em consideração: os prejuízos devido ao estresse hídrico; pragas, doenças e ervas daninhas; restrições climáticas sobre componentes de produção, formação de potenciais de produtividade e qualidade do produto; e os prejuízos devido às restrições de trabalhabilidade (todas as operações culturais) (FAO, 1978). A penalização para a produção pode ser:

Nula ou fraca: sem perda significativa;

Moderada: perda de 25\%;

Severa: perda de $50 \%$.

A produtividade agroclimática (FAO, 1978) leva ainda em consideração a classificação de zonas agroclimáticas, que, em função das perdas, possuem quatro classes de adequabilidade:

Plenamente apta, quando a produtividade agroclimática for igual ou superior a $80 \%$ da produtividade máxima;

Apta, quando a produtividade agroclimática estiver entre 80 e $40 \%$ da produtividade máxima;

Marginalmente apta, quando a produtividade agroclimática estiver entre 40 e 20\% do produtividade máximo;

Inapta, quando a produtividade agroclimática for inferior a 20\% da produtividade máxima.

A partir do mapa brasileiro de solos acessado pelo Instituto Brasileiro de Geografia e Estatística (IBGE), foi possível identificar o tipo de solo ocorrente na área avaliada, bem como determinar o tipo de relevo. 
Após a penalização e classificação com base no período de desenvolvimento da cultura, procedeu-se à análise da restrição edáfica de produção, que foi adaptada do modelo utilizado pela Food and Agriculture Organization of the United Nations- FAO (1978), o qual considera três restrições edáficas:

Classe S1: Classe adequada para produção agrícola, que não apresenta limitações à produção das culturas da soja e milho, portanto, a classe permanece a mesma do zoneamento agroclimático;

Classe S2: Classe adequada para produção, mas apresenta limitações que podem provocar decréscimos na produtividade e, portanto, foi considerada a classe imediatamente inferior ao zoneamento agroclimático;

Classe N: Extrema limitação de produção e, portanto, a área é considerada inapta para o cultivo.

Penalização da produção: Para penalização com relação à textura, utilizou-se o modelo da FAO (1978), em que solos com textura arenosa decrescem para a classe imediatamente inferior do zoneamento agroclimático, exceto para Neossolos e Espodossolos, cuja penalização por textura já está inserida na própria restrição da classe de solo.

A última penalização da produtividade foi realizada com base no relevo do solo, considerando as seguintes classes de relevo (EMBRAPA INFORMÁTICA AGROPECUÁRIA, 2002):

Relevo plano: Superfície de topografia esbatida ou horizontal, onde os desnivelamentos são muito pequenos, com declividades variáveis de 0 a 3\%;

Suave ondulado: Superfície de topografia pouco movimentada, constituída por conjunto de colinas ou outeiros (elevações de altitudes relativas até $50 \mathrm{~m}$ e de 50 a 100m), apresentando declives suaves, predominantemente variáveis de 3 a $8 \%$;

Ondulado: Superfície de topografia pouco movimentada, constituída por conjunto de colinas ou outeiros, apresentando declives moderados, predominantemente variáveis de 8 a 20\%;

Forte ondulado: Superfície de topografia movimentada, formada por outeiros ou morros (elevações de 50 a 100m e de 100 a 200m de altitudes relativas) e raramente colinas, com declives fortes, predominantemente variáveis de 20 a 45\%;

Montanhoso: Superfície de topografia vigorosa, com predomínio de formas acidentadas, usualmente constituídas por morros, montanhas, maciços montanhosos e alinhamentos montanhosos, apresentando desnivelamentos relativamente grandes e declives fortes ou muito fortes, predominantemente variáveis de 45 a 75\%;

Escarpado: Áreas com predomínio de formas abruptas, compreendendo superfícies muito íngremes, tais como: aparados, itaimbés, frentes de cuestas, falésias, vertentes de declives muito fortes, usualmente ultrapassando $75 \%$.

\section{RESULTADOS E DISCUSSÃO}

Os cálculos de evapotranspiração real da cultura evidenciaram que a duração do período úmido nas safras avaliadas não foi totalmente adequada para a produção da cultura de milho.

Os dados de temperatura máxima e mínima $\left({ }^{\circ} \mathrm{C}\right)$, precipitação $(\mathrm{mm})$, umidade relativa do $\operatorname{ar}(\%)$ referentes às três safras de milho, estão apresentados na Figura 3. 
Figura 3 - Dados mensais de temperatura máxima e mínima, umidade relativa do ar e precipitação referentes às safras 2008/2009 (A); 2009/2010 (B) e 2010/2011 (C)
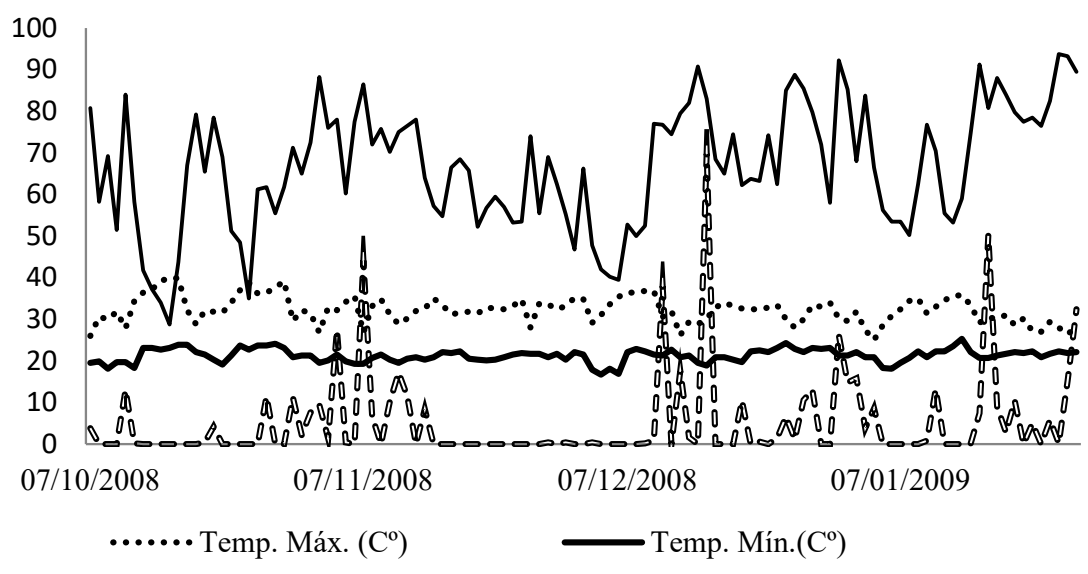

Umidade Relativa do Ar (\%) - ○० Precipitação (mm)
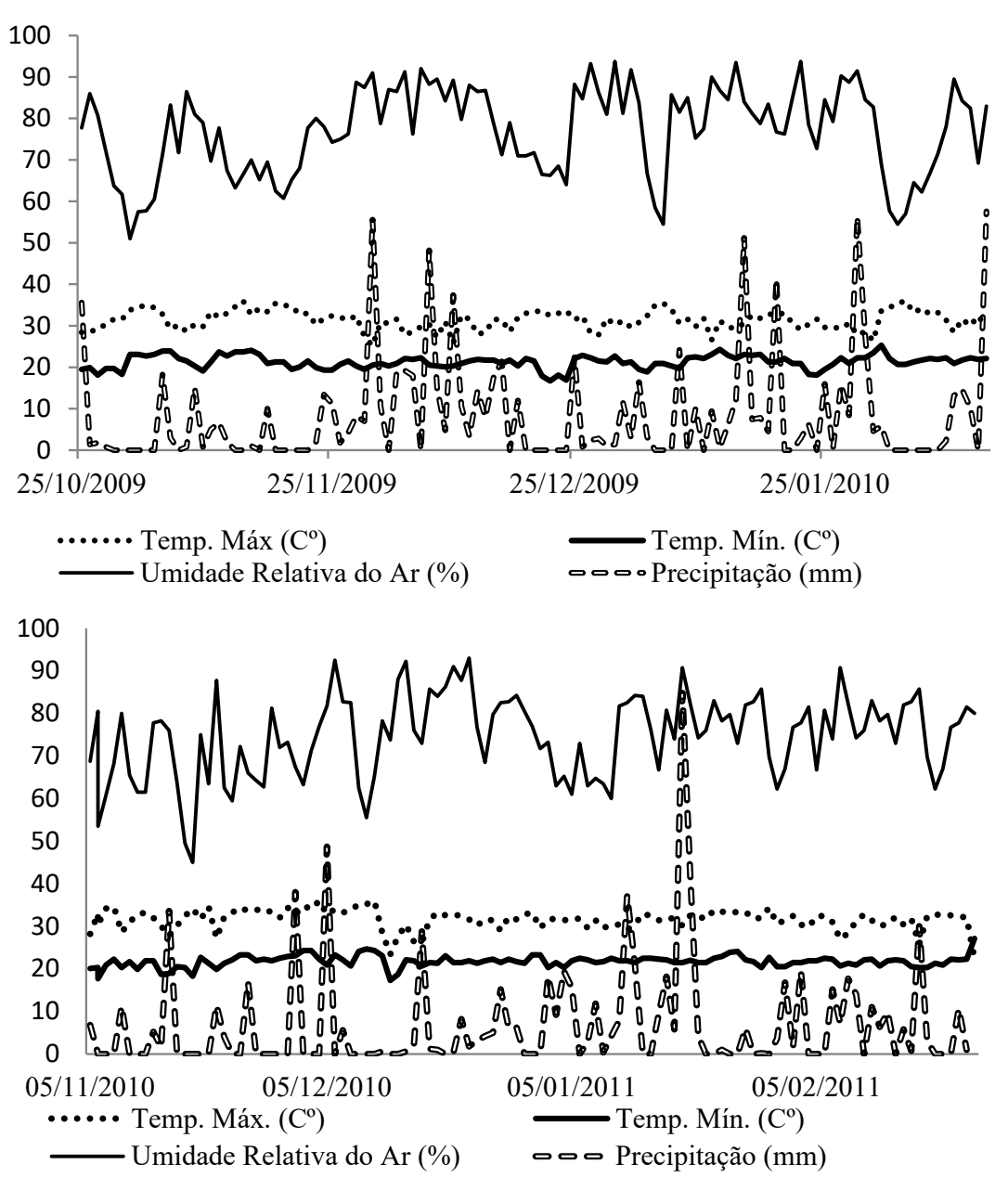

Fonte: Instituto Nacional de Meteorologia (INMET, s.d.).

A partir do mapa brasileiro de solos, a área produtora apresentou dominância de Latossolo vermelho distrófico (LVd) e relevo plano, sendo classificada como S1, que corresponde à classe adequada para produção agrícola, que não apresentam limitações à produção da cultura do milho, portanto as variações entre a produtividade real e as produtividades estimadas não poderão ser atribuídas a restrições edáficas e relevo. 
Na primeira safra de milho que compreendeu o período de outubro/2008 a janeiro/2009, somente para o mês de outubro o período para o cultivo não foi propício, pois apresentou evapotranspiração maior do que a precipitação no período, de acordo com o modelo de Camargo e Camargo utilizado para deduzir quais meses dentro de um ano agrícola são adequados para o cultivo (Figura 3).

Figura 4 - Precipitação e evapotranspiração real da cultura nas safras 2008/2009 (A); 2009/2010 (B) e 2010/2011 (C)
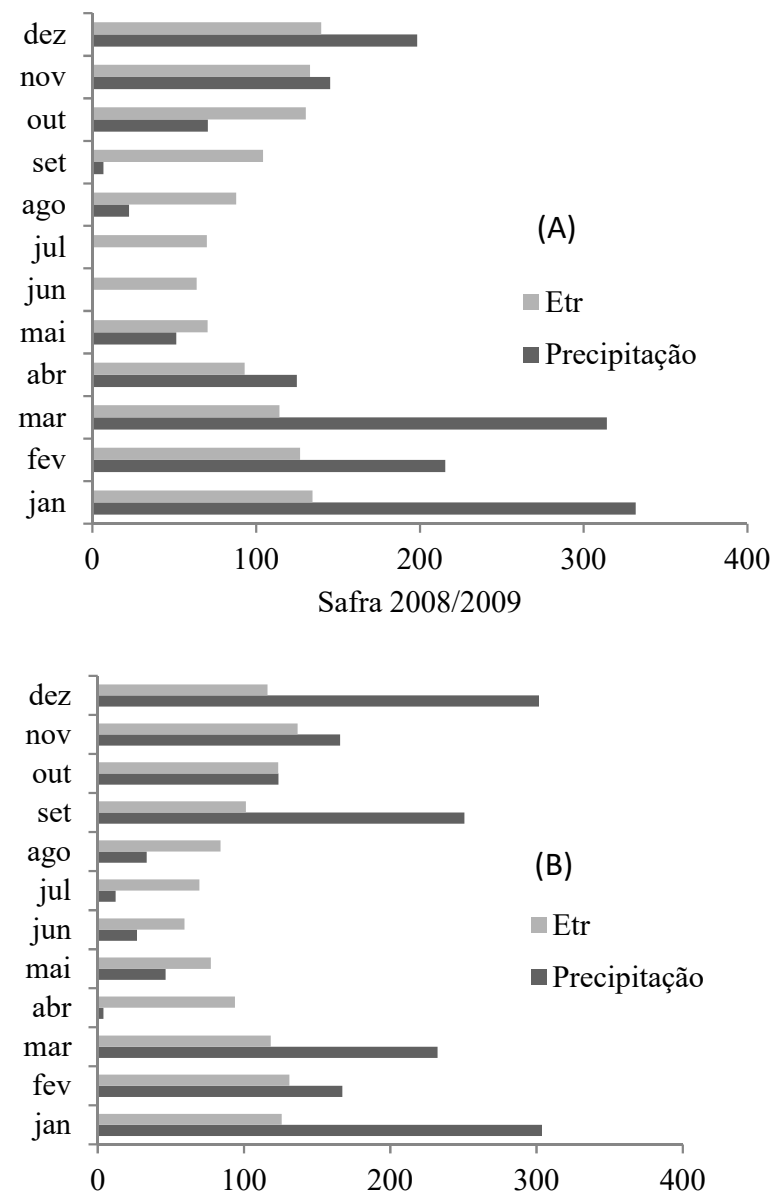

Safra $2009 / 2010$

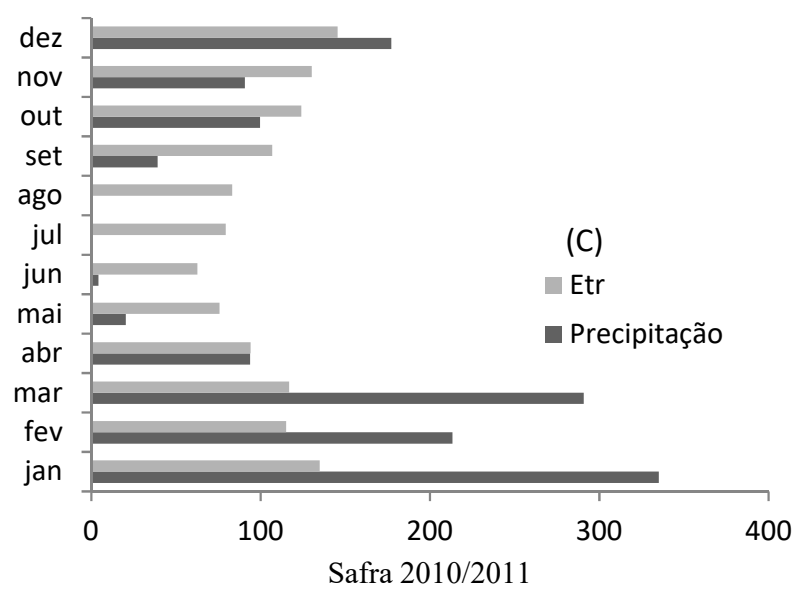

Fonte: Elaborado pelos autores (2014), com base em dados do Instituto Nacional de Meteorologia (INMET, s.d.). 
Assim, para a segunda safra de milho (outubro/2009 a fevereiro/2010), em geral, todos os meses foram propícios para o cultivo do milho e, na terceira safra de milho, que compreendeu o período de novembro/2010 a fevereiro/2011, o mês de novembro dentre os demais não foi propício. Após essa breve análise de períodos adequados ou não para o cultivo do milho nas três safras, observam-se os resultados obtidos por meio da penalização das produtividades (Figura 3).

A produtividade média do híbrido P30F53H avaliado comprova que as condições ambientais foram favoráveis na maioria dos meses, observando-se assim maior demanda hídrica na maioria dos meses de cultivo.

Diante da análise de penalização e, segundo a classificação da FAO (1978), considerando a duração do período disponível para o cultivo do milho (em dias), comparada com a safra 2008/2009, a safra 2009/2010 apresentou redução na produtividade (produtividade real) (Figura 4), considerada como perdas moderadas (25\%), referente a prejuízos devido às restrições de trabalhabilidade (todas as operações culturais), uma vez que a redução da produção não ocorreu por prejuízos devido ao estresse hídrico, a pragas, doenças e ervas daninhas ou restrições climáticas.

O conjunto de dados observados e estimados evidenciou que a estimativa de produtividade agroclimática foi mais próxima à produtividade real, em comparação ao cálculo de produtividade potencial (Figura 4).

Figura 5 - Comparação entre níveis de produtividade real de grãos de milho em três safras e produtividades estimadas por métodos agrometeorológicos

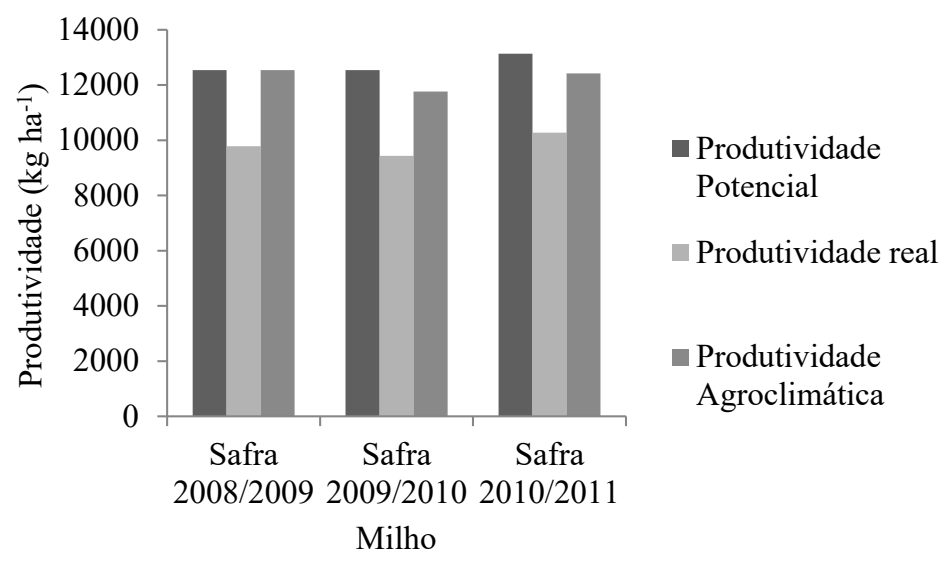

Fonte: Elaborado pelos autores (2014).

A Tabela 1 apresenta a descrição das safras e suas respectivas produtividades, evidenciando que o método de estimativa agroclimática para a região de estudo mostrou-se o melhor e eficiente para estimar a produção de milho para as referentes safras. 
Tabela 1 - Produtividade de grãos de milho em três safras consecutivas e diferença entre metodologias de avaliação. Produtividade agroclimática (PA), Produtividade potencial (PP), Produtividade real (PR)

\begin{tabular}{cccccc}
\hline Safra & $\begin{array}{c}\text { PA } \\
\left(\mathbf{k g ~ h a}^{-1}\right)\end{array}$ & $\begin{array}{c}\text { PP } \\
\left(\mathbf{k g ~ h a}^{-1}\right)\end{array}$ & $\begin{array}{c}\text { PR } \\
\left(\mathbf{k g ~ h a}^{-1}\right)\end{array}$ & $\begin{array}{c}\text { Diferença } \\
(\mathbf{P P}-\mathbf{P R}) \\
\left(\mathbf{k g ~ h a}^{-1}\right)\end{array}$ & $\begin{array}{c}\text { Diferença } \\
(\mathbf{P P}-\mathbf{P A}) \\
\left(\mathbf{k g ~ h a}^{-1}\right)\end{array}$ \\
\hline $2008 / 2009$ & 12538 & 12538 & 9780 & 2758 & 2758 \\
\hline $2009 / 2010$ & 11762 & 12537,84 & 9433,8 & 3104,04 & 2328,2 \\
\hline $2010 / 2011$ & 12423 & 13137,6 & 10278 & 2859,6 & 2145 \\
\hline
\end{tabular}

Fonte: Elaborado pelos autores (2014).

A produtividade de grãos de milho descrita na Tabela 1 apresenta maior valor de diferença na segunda safra da cultura, quando comparados os métodos de avaliação de produtividade potencial com a produtividade real obtida na área de estudos. Esse fato evidencia que os prejuízos podem estar atribuídos aos tratos operacionais da cultura (conforme a penalização de produtividade) apresentando maior impacto de redução na produtividade de grãos (kg ha-1) dessa cultura quando comparado com os prejuízos da última safra atribuídos à restrição hídrica no período de cultivo do milho.

Assim como no estudo de séries históricas de dados para classificação do zoneamento agrícola de riscos climáticos para a cultura do milho em Mato Grosso do Sul (BRASIL, 2017), a área de estudo foi classificada como zona climática plenamente apta para o cultivo na safra 2008/2009, uma vez que a produtividade agroclimática foi igual ou superior a $80 \%$ da produtividade máxima; e apta para as safras 2009/2010 e 2010/2011 (produtividade agroclimática entre 80 e $40 \%$ da produtividade máxima).

\section{CONCLUSÃO}

O método de produtividade agroclimática (FAO, 1978) mostrou-se eficiente para estimar a produtividade de milho, pois elucida os parâmetros que podem influenciar na redução de rendimento ao produtor. A metodologia caracterizou a área estudada como adequada para produção agrícola, suscitando que a redução de produtividade na safra 2009/2010, refere-se a prejuízos devido às restrições de trabalhabilidade (todas as operações culturais)

\section{REFERÊNCIAS}

BRACHTVOGEL, E. L.; PEREIRA, F. R. S.; CRUZ, S. C. S.;BICUDO, S. J. Densidades populacionais de milho em arranjos espaciais convencional e equidistante entre plantas. Ciência Rural, Santa Maria, v. 39, n. 8, p. 2334-39, nov. 2009.

BRASIL. Ministério da Agricultura, Pecuária e Abastecimento. Secretaria de Defesa Agropecuária. Zoneamento agrícola de risco climático. Brasília: MAPA/ACS, 2017.

CAMARGO, A. P.; CAMARGO, M. B. P. Teste de uma equação simples para estimativa da evapotranspiração potencial baseada na radiação solar extraterrestre e na temperatura do ar. In: CONGRESSO BRASILEIRO DE AGROMETEOROLOGIA, 3., Campinas. Anais[...]. Campinas: Sociedade Brasileira de Agrometeorologia, 1983. p. 229-44. 
DOORENBOS, J.; KASSAM, A. H. Yield response to water. Rome: FAO, 1979. 193p.

EMBRAPA INFORMÁTICA AGROPECUÁRIA. Agritempo - sistema de monitoramento agrometeorológico. Campinas: Embrapa Informática Agropecuária; Cepagri/Unicamp, 2002. Disponível em: http://www. agritempo.gov.br. Acesso em: 25 maio 2013.

FOOD AND AGRICULTURE ORGANIZATION OF THE UNITED NATIONS. Report on the agro-ecological zones project. Methodology and results for Africa. Roma: FAO, 1978. V. 2.

GALON, L.; TIRONI, S. P.; ROCHA, A. A.; SOARES, E. R.; CONCENÇO, G.; ALBERTO, C. M. Influência dos fatores abióticos na produtividade da cultura do milho. Revista Tropica-Ciências Agrárias e Biológicas, Chapadinha, v. 4, n. 3, p. 18, 2010.

INSTITUTO BRASILEIRO DE GEOGRAFIA E ESTATÍSTICA. Mapas. Rio de Janeiro: IBGE, 2009. Disponível em: http://mapas.ibge.gov.br/en/. Acesso em: 6 jun. 2013.

INSTITUTO NACIONAL DE METEOROLOGIA. Climatologia mapas. [online]. Brasília: INMET, [s.d.]. Disponível em: http://www.inmet.gov.br/portal/index.php?r=bdmep/bdmep. Acesso em: 23 maio 2013.

ROSA, V. G. C.; MOREIRA, M. A.; RUDORFF, B. F. T.; ADAMI, M. Estimativa da produtividade de café com base em um modelo agrometeorológico-espectral. Pesquisa agropecuária brasileira, Brasília, v. 45, n. 12, p. 1478-88, dez. 2010.

\section{Sobre os autores:}

Claudia Cardoso dos Santos: Doutora em Agricultura Tropical pela Universidade Federal de Mato Grosso (UFMT). Mestre em Engenharia Agrícola e Licenciada em Ciências Biológicas pela UFMT. E-mail: santosclaudiac@hotmail.com, Orcid: http://orcid.org/0000-0002-3182-6951

Glauce Portela de Oliveira: Doutora em Agricultura Tropical pela Universidade Federal de Mato Grosso (UFMT). Mestre em Agronomia pela Universidade Estadual do Sudoeste da Bahia (UESB). Engenheira Agrônoma pela Universidade do Estado de Mato Grosso (UNEMAT). Professora do Curso de Engenharia Agrícola e Ambiental do Instituto de Ciências Agrárias e Tecnológicas (ICAT).

E-mail: glauceoli@gmail.com, Orcid: http://orcid.org/0000-0003-1838-4463 